\title{
Soy dibujante de hojas en blanco
}

\section{I am a cartoonist of blank sheets}

\author{
Mari Carmen Díez Navarro*
}

Recibido: 25 de enero de 2022 Aceptado: 26 de enero de 2022 Publicado: 31 de enero de 2022

To cite this article: Díez Navarro, Mª C. (2022). Soy dibujante de hojas en blanco. Márgenes, Revista de Educación de la Universidad de Málaga, 3(1), 178-180

DOI: http://dx.doi.org/10.24310/mgnmar.v3i1.14170

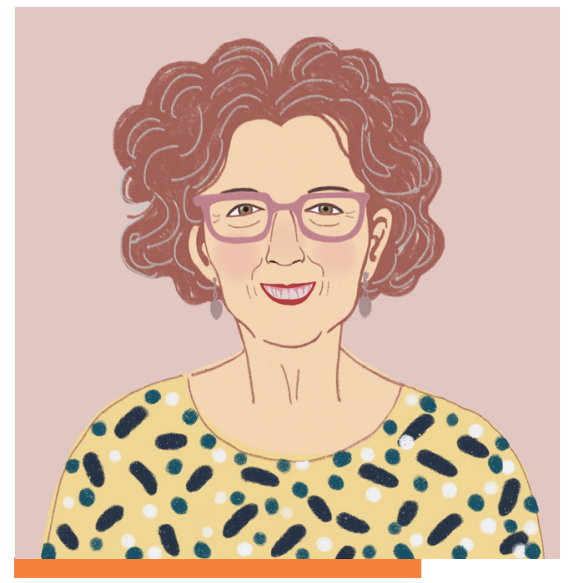

Mari Carmen Díez Navarro

\section{RESUMEN}

La mirada adulta, sea la de un maestro o una maestra, o la de padres y madres, constituye una referencia fundamental en el proceso de estar y crecer en el mundo. Nuestra autora nos invita a pensar, a partir de las historias de dos niños en su relación con el acto de creación artística, acerca del importante lugar que ocupamos en esos primeros pasos en el mundo. Pasos en lo que están en juego, ni más ni menos, sus primeras experiencias de reconocimiento y autoconfianza.

Palabras clave: educación infantil; pedagogía; expresión artística; confianza

\section{ABSTRACT}

The adult gaze, either that of a teacher, or that of parents, is a fundamental reference in the process of being and growing up in the world. Our author invites us to think, on the basis of the stories of two children in their relationship with the act of artistic creation, about the important place we occupy in those first steps in the world. Steps in which are at stake, no more and no less, their first experiences of recognition and self-confidence.

Keywords: childhood education; pedagogy; artistic expression; trust

"Soy dibujante de hojas en blanco"

Así les dijo Emiliano a sus padres hace unos días. Tiene tres años y este curso ha empezado a ir a la escuela. El año pasado se mostró interesado en los dinosaurios, después quiso hacer letras como las que escribía su mamá, luego estuvo imitando exhaustivamente a sus dos perros y ahora lo que quiere es dibujar. Va cambiando de intereses según le marcan sus inquietos deseos y su enorme curiosidad. 
H ISTORIAS MÍN I MAS

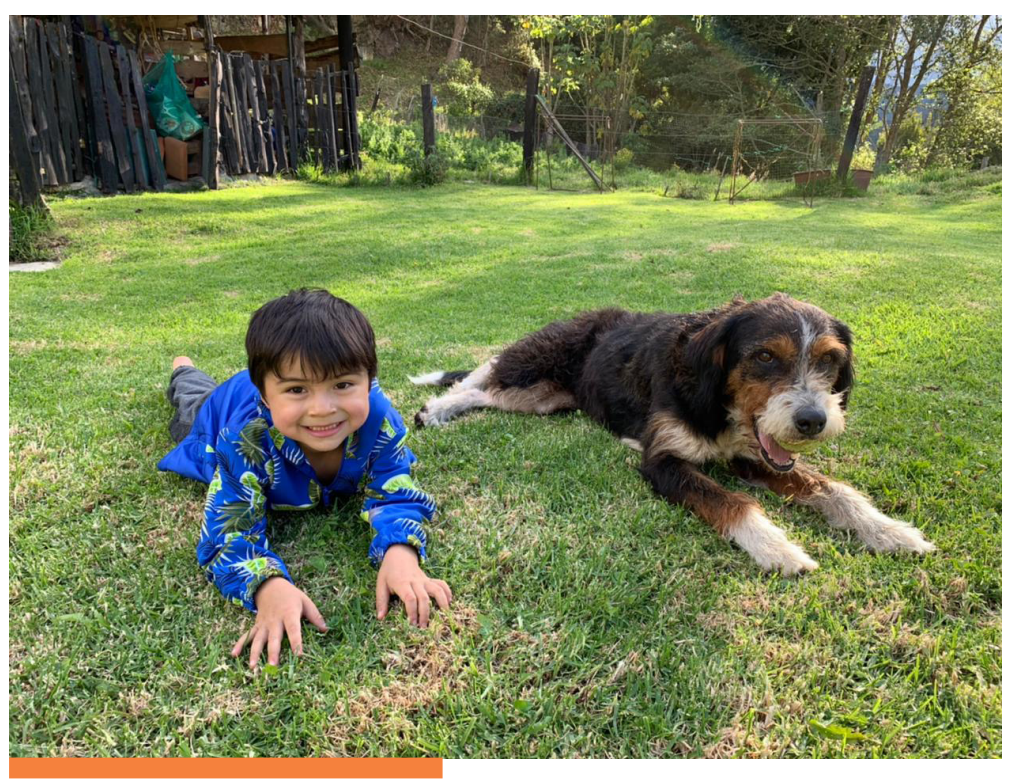

Créditos: Carolina Molano

En esto del dibujar especifica con claridad que quiere las hojas en blanco, sin pautas, sin dibujos medio hechos, sin puntitos para repasar. Quiere dibujar como le dicten sus imaginativos anhelos y como le respondan sus dedos, aún inmaduros e inhábiles. Él necesita dibujar desde adentro y poder reconocer como propios los trazos que salen de su mano. No tiene miedo, se siente seguro y capaz. Y lo será, siempre que no se le pretendan cosas que excedan sus posibilidades y sus ganas.

Emiliano me ha hecho pensar en Gabriel, un niño que vino de otra población para asistir unos meses a nuestra escuela mientras su padre trabajaba en una obra en la que le habían dado empleo. Tenía cinco años y también era curioso y juguetón, como Emiliano. Se llevaba bien con los compañeros, sabía decir su opinión y defenderla, tenía buen humor... Sin embargo, cuando yo proponía hacer un dibujo y repartía las hojas en blanco, Gabriel perdía su aplomo, se ponía a temblar y me pedía que le hiciera "la rayita”, porque "si no veía la rayita, no podía hacer nada".

Las primeras veces le aclaré que en esta escuela cada persona dibujaba como sabía y que a mi me gustaban los dibujos de todos, porque siempre eran diferentes y bonitos. Le animé vivamente a dibujar, pero él tenía tanta dificultad que no se atrevía. Una de las veces incluso se puso a llorar. Así que pedí que algún amigo lo ayudara hasta que consiguiera dibujar por si mismo. De modo que alguien le hacía "la rayita" y él rellenaba de color la silueta, como
"Él necesita dibujar desde adentro y poder reconocer como propios los trazos que salen de su mano. No tiene miedo, se siente seguro y capaz." 


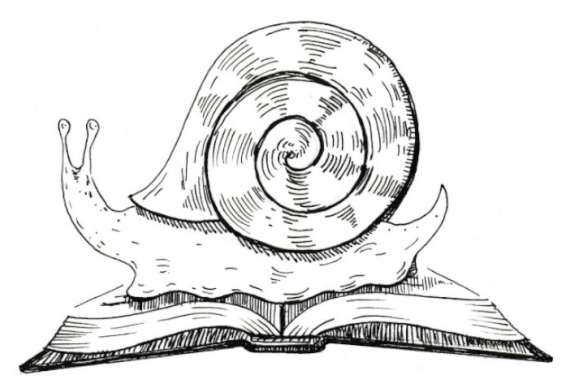

le habían enseñado en la escuela de su pueblo. Ésta solía ser su costumbre el tiempo que estuvo en mi clase, hasta que un día se animó a dibujar un pájaro a gran tamaño y con las plumas de colores, como uno que había visto en el zoo, lo cual provocó que todos los niños y niñas le dieran un sentido aplauso, al cual me adherí contentísima.

Los padres me explicaron que la maestra que tenía era muy exigente y le rompía los trabajos si consideraba que estaban mal hechos. Decían que en el colegio el niño estaba atemorizado, que parecía otro y que cada vez que no iba a clase se relajaba tanto que hasta canturreaba. Pero que como no había otra escuela en el pueblo, "tenía que acostumbrarse". Les expliqué como mejor supe que este tiempo era importante para Gabriel, ya que es cuando se adquiere confianza en uno mismo, cuando se despierta el deseo de aprender, cuando se aprende a expresar hacia fuera lo que se piensa y se siente por dentro... Y que convendría que hablaran con la maestra y le pidieran que frenara su excesiva demanda con Gabriel.

También les pedí que estuvieran pendientes del niño y valoraran todo lo que pudieran sus producciones. En fin, les dije lo que se me ocurrió, incluyendo la posibilidad de visitar al inspector de su zona para que se tomara interés en las consecuencias de la actitud tan rígida de una maestra que trabajaba con niños pequeños. No he sabido más de Gabriel. Espero que le haya ido bien. Pero qué sufrimiento tan vano, qué manera de empezar la escolaridad tan triste, qué idea de la escuela tan agobiante que se formaría este niño y quizás algunos de sus compañeros por la férrea actitud de la maestra.

Si los primeros dibujos que hicieran los niños fueran realmente abiertos, de exploración, de expresión, de descubrimiento, difícilmente se asustarían. Si la actitud de los adultos fuera de valoración de sus producciones, irían llenándose de seguridad y autoestima. Si los niños pudieran ir recorriendo el camino que va desde el garabateo hasta el dibujo representativo, sin que nadie les dijera que lo que hacen no está bien hecho, todo sería un devenir placentero para ellos.

Teniendo en cuenta, además, que no es en absoluto cierto que lo que hacen esté mal. Están sencillamente caminando. Es el primer momento de un largo proceso 
que no hay que evitar ni interrumpir, sino solo provocar y acompañar. Si se diera una buena acogida a las probaturas de los niños sobre el papel y no un aleccionamiento hacia el relleno de color, el repaso de líneas o puntos y los dibujos estereotipados a copiar, seguramente los niños no tendrían nunca la sensación de que no saben dibujar, sino todo lo contrario. Por si faltaba algo, hace mucho que se nos viene diciendo que "artista se nace”, que crear es algo difícil y restringido, que sólo hay una minoría de privilegiados creadores... Y como el inicio a los trabajos plásticos es de la forma que estamos comentando, efectivamente así se sigue dando.

Por suerte en la escuela infantil vemos que cualquier niño tiene capacidades creativas y que el mejor modo de aprender a crear es empezar desde bien temprano a recorrer caminos nuevos. No hay más que ver a los niños embebidos en sus mil y un tejemanejes, mezclas e inventos. En sus producciones de todo tipo: ciudades hechas con maderitas, casas para hormigas en el arenero, "cemento puro" hecho con el barro del patio, secretos, pinturas... Producir es derramarse, sacar fuera nuestra particular manera de percibir, de recordar, de sentir, mostrar cómo transformamos las vivencias en materiales inéditos, recién nacidos, acabados de crear. Hacer aparecer un producto de la nada tiene un punto de magia y de sorpresa que produce una sensación placentera, activa, alegre que llama a seguir y a disfrutar.

Pero aunque se nace curioso, y ávido de placer, esos impulsos pueden quedar en nada si no se da paso a la expresión libre del niño. Si no se alienta, protege y espera el producto nuevo, o reinventado por cada cual. Y entonces, según se reciba ese nuevo producto, según se valore, se seguirá adelante, o se dedicará uno a repetir lo conocido. A veces la alegría de probar, de curiosear, de jugar con los personajes o formas que aparecen en los dibujos, hace que el autor hable con ellos mientras los va dibujando. O que cante. O que sonría. O que se complazca al ver su obra. Sin embargo, en otras ocasiones el miedo a equivocarse, a no contentar a los adultos, a no hacerlo todo tan perfecto como se desearía, lleva a algunos niños a frenarse y a bloquear su mano, su imaginación y su confianza.

La mirada de los otros siempre será un importante punto de referencia y de apoyo para atreverse a avanzar,

\section{"Producir es} derramarse, sacar fuera nuestra particular manera de percibir, de recordar, de sentir, mostrar cómo transformamos las vivencias en materiales inéditos, recién nacidos, acabados de crear.' 


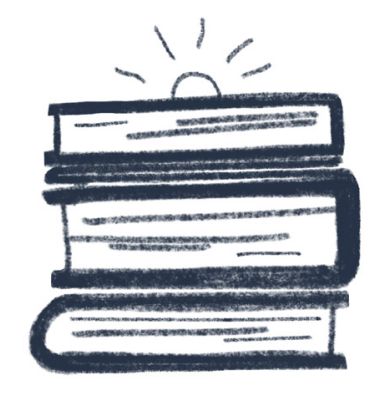

para confiar en las propias posibilidades, para notarse aceptado. No es cualquier cosa, pues, recibir un dibujo de un niño. En él va puesto su sello, su nombre, su estilo, su madurez, su gusto, su ser. Importante papel, pues, el de nuestra mirada de maestros o de padres. Ha de estar. Ha de acoger. Porque si para cualquiera de nosotros es importante lo que decimos, lo que pensamos y lo que hacemos, mucho más lo es para los niños en sus primeras edades. Los productos que salen de ellos están revestidos de una fuerte capa de narcisismo, que habrá que cobijar lo mejor que podamos para que los niños sientan que lo que sale de si mismos es bien recibido. O lo que es lo mismo, que ellos son valiosos ante los demás.

No podemos dejar al azar el hecho de que un niño disfrute dibujando en las hojas blancas, como Emiliano. O que otro sufra al ver sus hojas rotas por no estar bien hechas, como Gabriel. Porque esto no es cuestión de suerte, esto depende de nosotros, los maestros, de nuestras metodologías, actitudes y planteamientos.

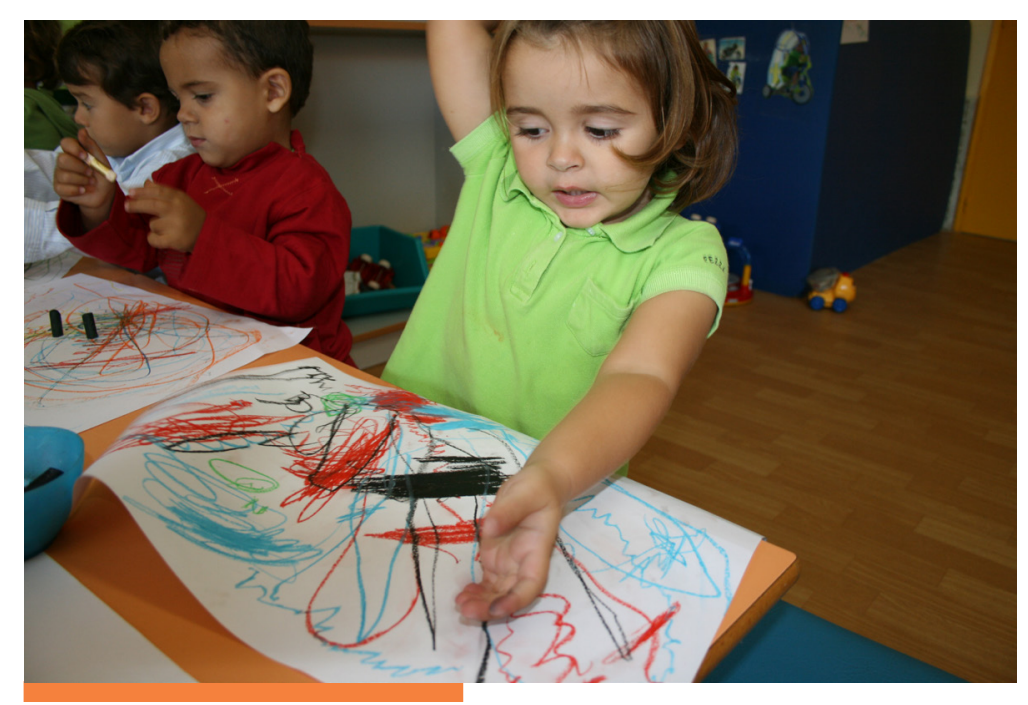

Créditos: Reme Picó 